\section{A Disruptive Partnership Connecting Academia, Science and the Profession}

Scott Poole

University of Tennessee
Initiated in April, 2014, The Governor's Chair for Energy + Urbanism was a $\$ 2.25 \mathrm{M}$ five-year research partnership between the University of Tennessee, Knoxville, Skidmore, Owings \& Merrill, a prominent architecture, interior design, urban planning, and engineering firm with an extensive global practice, and Oak Ridge National Laboratory (ORNL, located near Knoxville, TN, the largest U.S Department of Energy science and technology laboratory. ${ }^{1}$

While the partnership had multifaceted objectives, they all, in one way or another, had to bridge the prevailing disconnect between academic inquiry, basic scientific research, and practical application

\section{OVERCOMING INERTIA}

Viewed from the perspective of our college, The Governor's Chair for Energy + Urbanism was a disruptor.

It arrived suddenly, challenged the status quo, and fostered change at an uncomfortable pace. High-level design professionals, distinguished scientists, and innovative industries do not typically work side-by-side with faculty and students. The Governor's Chair program provided that opportunity.

- It urged us to rethink our tendency to work in isolation and to become more interconnected;

- It challenged the normalcy of a curriculum that placed too much focus on individual performance by stressing the importance of multidisciplinary team building;

- It called out the limited educational utility of small-scale projects and compelled us to investigate large, complex systems; and

- It questioned our reliance on traditional methods of fabrication by accelerating the adoption of new computational design tools to speed the development of a more vibrant maker culture.

From the beginning, the joint partners recognized that each of us had an ongoing enterprise with embedded inertia. This was certainly the case for our college. Academicians in archit. are notoriously resistant to change and can be ironically distanced from the professional world. Likewise, scientists in national laboratories are laser focused

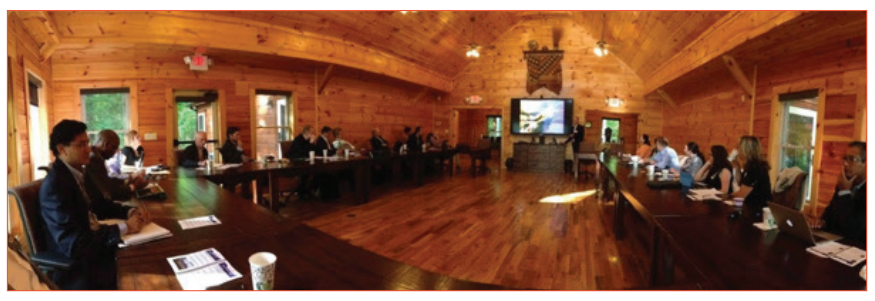

Figure 1. Cabin meeting at Oak Ridge National Lab, August 2014, convening academics from the University of Tennessee, Scientists and engineers from ORNL, and planners from Skidmore, Owings \& Merrill. 
on making scientific breakthroughs but rarely include designers on their multidisciplinary teams as they work to translate basic science to commercial innovation. And architecture firms, who are in the business of making compelling buildings and shaping future cities, seldom include scientists or academicians in their visioning process.

Clearly, our first challenge was to overcome our propensity to operate in isolation.

Some of the biggest successes in our college, and many colleges of architecture and design throughout the U.S. occur by faculty partnering with colleagues in their own college, across colleges, with local and global stakeholders. ${ }^{2}$ That is precisely why we began the Governor's Chair with the motto: What can we do together that we cannot do alone?

\section{BEGINNING AMBITIOUSLY SMALL}

That simple question, What, can we do together that we cannot do alone? reminded each of us of our institutional limitations, and immediately put our work into perspective. It framed a type of project that would stretch our imagination, test our creative capacities, and extend the reach of our resources. We began ambitiously small. By beginning with a relatively small-scale project, we could leverage many of our sophisticated capacities, pull the team together, understand our strengths and weaknesses, and engage the industry partners we would need going forward.

In October 2014, leaders from Oak Ridge National Laboratory, Skidmore, Owings \& Merrill, SOM, the University of Tennessee, Knoxville, and key industry partner Clayton Homes met to discuss the idea for building an innovative housing prototype. Soon, AMIE, an acronym for Additive Manufacturing Integrated Energy emerged.

While the timeline established for the AMIE prototype was wildly optimistic, the team was confident that we could move from a sketch on a restaurant receipt to a proof of concept in less than 11 months by using Oak Ridge National Laboratory's Big Area Additive Manufacturing facility to accelerate production of the prototype. By mid-September 2015, 46 weeks from our initial meeting, a 3D-printed prototype that wirelessly reciprocated energy between a dwelling prototype and a vehicle was complete and ready for display at ORNL's annual industry day. At this early stage, little more than a year into our partnership, more than 100 architects, engineers, scientists, students, and fabricators had been involved in the AMIE prototype. Over the next several years, it was recognized with national and international awards including recognition as a finalist in the World Changing Ideas Awards by Fast Company (2016, an R+D Award from Architect Magazine (2017, and in June, 2019, it was a finalist in the 3D Pioneers Competition.

The AMIE prototype achieved, at the building scale, an important aspect of our ambitious project for reimagining dense, mobility-rich,
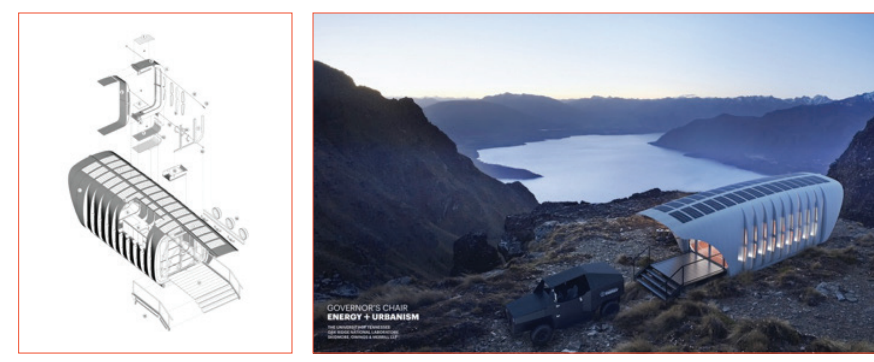

Figure 2. AMIE prototype: Exploded Axonometric. (2015)

Figure 3. AMIE (Additive Manufacturing Integrated Energy) rendering. (2015)

energy-efficient, healthy, and resilient cities that draw from and contribute to the rich network of natural systems they are part of. It was a first step in realizing our vision to leverage the Governor's Chair to create a nationally recognized energy and urbanization partnership focused on tackling three big challenges at three scales.

- Technical innovation at the scale of buildings and infrastructure

- Livability advances at the scale of neighborhoods / city districts

- Environmental stewardship from the scale of the city to multi-state watersheds

\section{INVESTIGATING LARGE COMPLEX SYSTEMS}

Following the AMIE prototype, the Governor's Chair studios continued to work at the scale of details, buildings, and districts, but it also began new work, The River Studio, at the scale of the complex interconnected networks that characterize our vast regional ecosystem. Led by Governor's Chair Phil Enquist and UT Associate Professor Brad Collett, The River Studio, conducted first-hand research by travelling the 652-mile length of the Tennessee River from Knoxville, TN to Paducah, KY. The purpose of the studio was to create 10 visions for the future of the river by studying its ecosystem, interviewing a range of the $4.5 \mathrm{M}$ people who live and work within the river's watershed, examining challenges to industry, and seeking opportunities for economic development.

The River Studio became a catalyst for today's Tennessee

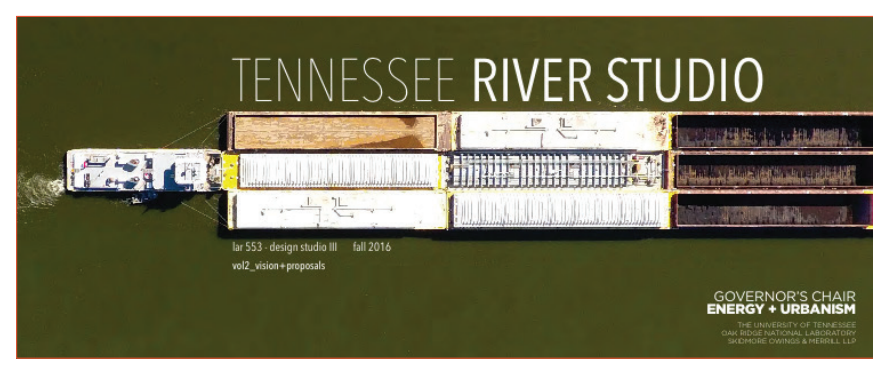

Figure 4. Tennessee River Studio (2016). Led by Assoc. Professor Brad Collett with Governor's Chair Phil Enquist. 
RiverLine a vision for a system of multi-modal trail experiences connecting the 31 counties and dozens of cities, towns, and rural communities touched by the river. The Tennessee RiverLine Partnership, which includes National Park Service, the Nature Conservancy, and the Tennessee Valley Authority, has grown, in 2019, to include scholars, planners, agency leaders, tourism professionals, and non-profit directors. Just this month, five communities in four states along the Tennessee river were selected as pilot communities for Tennessee RiverLine, the beginning of what is likely to be a multi-generational project

\section{ESTABLISHING A VIBRANT MAKER CULTURE}

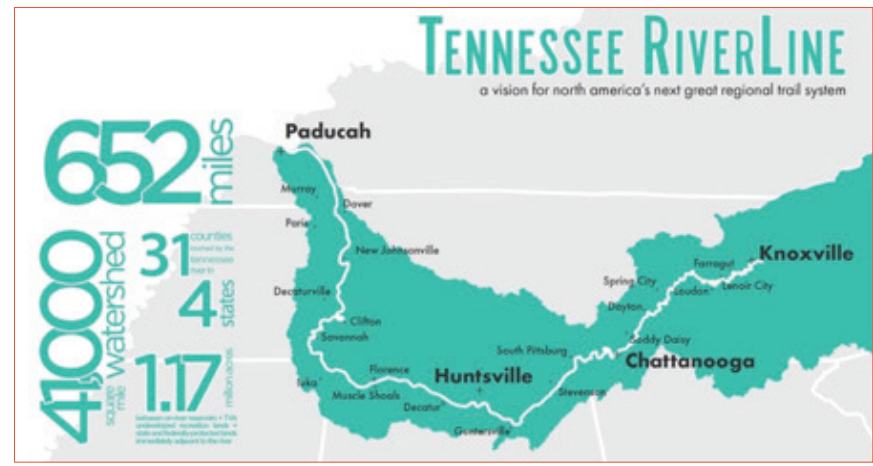

Figure 5. Tennessee RiverLine. Fact sheet from studio led by Assoc. Prof. Brad Collett. (2018-present)

In 2012, Knoxville emerged as a prominent "Maker City" is what began to be called the "Maker Belt," a region of creative fabrication stretching from Knoxville, Tennessee to Louisville, Kentucky. Anticipating this emerging phenomenon and recognizing the need to establish a more vibrant maker culture among our students, the college began negotiations, in 2012, for a 20,000-square-foot multi-purpose maker space--now known as the Fab Lab. By spring 2014, the building was acquired and immediately equipped with advanced computational design technologies, providing state-of-the-art resources for our students and a home for the Governor's Chair.

Through the Governor's Chair program our students, faculty, and professional partners continue to witness--through our ongoing connection to scientists at Oak Ridge National Laboratory's Big Area Additive Manufacturing facility--the rapidity of innovation in emerging technologies. They experience how quickly information from one prototype is translated into new solutions, how fast new technologies become obsolete, and how swiftly researchers and designers have to adapt to this accelerating tempo.

Similarly, through our ongoing work making full-scale prototypes in the micro-factory of industry partner Local Motors, our faculty and students, led by UT Distinguished Lecturer James Rose, continue to have the unusual opportunity to have hands-on experience with the latest additive manufacturing technologies, while being directly exposed to the excitement, uncertainty, risk and agility of an emerging industry leader working at the forefront of two innovations--additive manufacturing and autonomous mobility.

\section{TRANSFORMATIVE IMPACT}

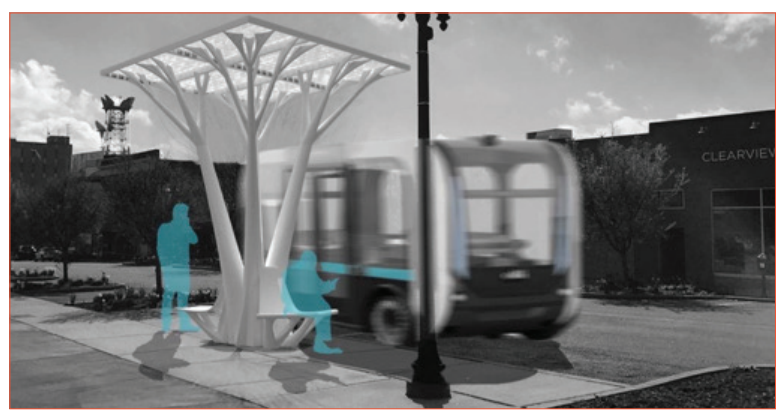

Figure 6. Dendrite Biomorphic - 3D Printed Charging Station (2018). Designed by University of Tennessee College of Architecture + Design students for LM Industries' fully realized autonomous vehicle, Olli. ${ }^{3}$

The Governor's Chair program had a transformative impact on the College of Architecture and Design.

Essentially, the program operated as a skunkworks, a design environment characterized by a loose structure, relative independence, and a focus on innovation and impact at scales ranging from a 240 -square-foot 3D-printed building prototype to ecological stewardship and economic development across the 41,000-square-mile watershed of the Tennessee River.

Regardless of scale, the projects were typically characterized by

- an immediate emphasis on dialogue; team-building, and goal-sharing;

- collaboration across disciplinary boundaries;

- expert advice from high-level consultants;

- support from industry partners critical to the success of the mission;

- exposure to innovative products and emerging technologies.

The Governor's Chair program helped establish networks and opportunities that will benefit our college far into the future. Through our joint partnership with SOM and ORNL we developed important working relationships with an internationally prominent architecture firm, its network 
of world-class consultants and a renowned national laboratory. Dialogue was established, building bridges between the sciences and the arts--disciplines that typically have little to say to each other. And industry partnerships were initiated providing significant links to next-generation technologies.

These new networks changed our college's ambition, outlook, and research potential by opening up access to prominent partners for future projects. Students and faculty were given the rare opportunity to work side by side with architects, scientists, engineers, and designers working together as a transdisciplinary team on world-class research. They witnessed a project evolve from a rough sketch to an internationally acclaimed building in less than 11 months. They secured jobs and internships. And more than 100 students in a dozen design studios had the opportunity for constant contact with high-level professionals and other recognized experts who regularly critiqued their work, elevated their expectations and increased performance.

\section{ESSENTIAL DISRUPTION}

By encouraging an environment of experiment and risk, of wonder and curiosity, a culture that values the new, the untried, and the unfamiliar, the Governor's Chair program was a force in the transformation of the creative culture of our college. Adapting to the speed of this transformation was often difficult and required agility, but it engaged students and faculty with new tools, new materials, and new processes of manufacture. It helped us to recalibrate our approach to the value of multi-disciplinary teams. And, finally, we learned that working with disruptors is something we should not evade. In fact, positive disruption will be essential as change in the design industry happens even more quickly than it does today, compelling us to rethink what we teach and how we teach.
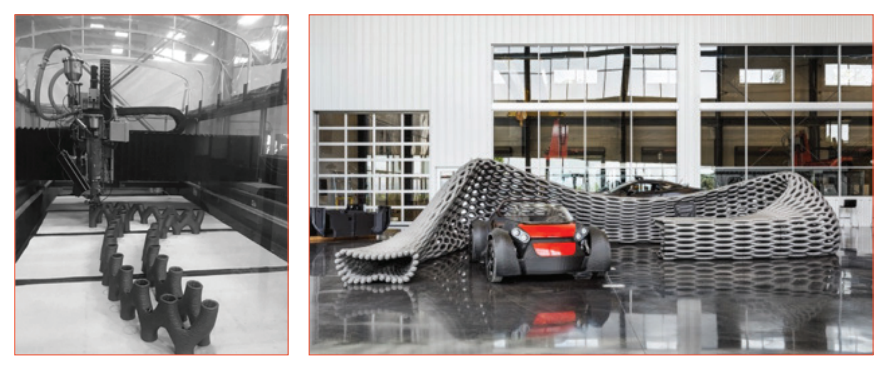

Figure 7. Thermwood Large Scale Additive Manufacturing (LSAM) machine producing section for AMPD at LM Industries.

Figure 8. AMPD (Additive Manufacturing Parametric Design). Large-Scale 3D Printed reception area for LM Industries (Local Motors) Knoxville. (2017-18). ${ }^{4}$

\section{Notes}

1. Recognizing the increasing importance of scientific research and technology to the well-being of the state's economy and environment, former Governor Phil Bredesen initiated the Governor's Chair initiative in 2006, in an effort to broaden, deepen, and further stimulate the unique research partnership that exists between the state's flagship university, the University of Tennessee, and Oak Ridge National Laboratory, the nation's largest multi-program laboratory. The purpose of this high-profile program was to increase the potential for scientific breakthroughs and the development of new technologies by recruiting nationally and internationally prominent scientists and engineers to advance existing research capabilities and build new areas of strength. The promise was that these distinguished researchers would elevate the joint research capacity of UT and ORNL. From the beginning, in 2006, over a dozen Governor's Chairs have been appointed in areas ranging from material science and environmental biology to electrical engineering and energy storage.

2. Examples include Auburn's Rural Studio, Virginia Tech's design/buildLAB, University of Kansas' Studio 804, and more. As well as the national and international Solar Decathlon competitions involving universities from around the globe over the past twenty years.

3. The Dendrite Biomorphic Prototype - 3D Printed Charging Station was designed by Cody Grooms, Zane Russell, and Jacob Wakefield.

4. The prototype for AMPD project was designed by a team including: Kristia Bravo, Stephanie Robertson, Britton Virden, Kyra Wu, Pruitt Smith, and Kayla Adams. The final version of AMPD, led by Kristia Bravo, was printed in 28 segments and the final assembly post-tensioned. Each segment took four hours to print and the project was completed in one week. After material optimization the weight was reduced from 9,000 lbs. to 5,000 lbs. Parametric programs: Rhino and Grasshopper. Material: ABS plastic, reinforced (20\%) by glass fiber pigmented by aluminum powder. 